\title{
Central nervous system involvement in progressive muscular dystrophy
}

\author{
MIEKO YOSHIOKA, TAKEHIKO OKUNO, YOSHIHITO HONDA, AND YOSHIHISA NAKANO
}

Department of Paediatrics, Department of Ophthalmology, and Department of Radiology, Kyoto University, Medical School and Hospital, Japan

SUMMARY Several abnormalities in the central nervous system were shown in patients with progressive muscular dystrophy using computerised tomography (CT) scans, electroencephalograms, psychometry, and ophthalmological methods. In congenital muscular dystrophy, the most characteristic finding in the CT scan was a low density area in the white matter, seen in $14(56 \%)$ out of 25 cases. In Duchenne dystrophy, slight cerebral atrophy was observed in 20 (67\%) out of 30 cases. It was interesting that in the case of Duchenne dystrophy the older the patient, the more severe were the CT findings. In congenital muscular dystrophy half the patients with a low density area showed a spike or a spike-and-wave complex in the electroencephalogram, and optic atrophy was evident in several cases. It is concluded that progressive muscular dystrophy is not only a myogenic disorder but also one which affects the central nervous system.

Progressive muscular dystrophy is considered to be a myopathic disorder. Rosman and Kakulas ${ }^{1}$ made a detailed neuropathological study of 12 cases and found abnormalities of cerebral development in patients in whom mental deficiency was present in addition to the muscular dystrophy. At necropsy examination of 8 cases of congenital muscular dystrophy (CMD) in Japan, ${ }^{2-5}$ striking dysplastic abnormalities of the brain - such as diffuse cerebral and cerebellar micropolygyria, temporal agyria, and abnormal fusion of hemisphere at the frontal lobes-were found. In this paper, we use the term congenital muscular dystrophy for the Fukuyama type of CMD, ${ }^{6}$ and such is characterised by the early onset of hypotonia, involvement of facial muscles, joint contracture, severe mental retardation with occasional convulsions, and a slowly progressive course. Autosomal recessive inheritance, increased serum creatine phosphokinase activity, a myogenic pattern on the electromyogram, and dystrophic abnormalities in muscle biopsy justify the disease being classified as a form of muscular dystrophy.

We studied central nervous system involvement in patients with CMD and Duchenne dystrophy using computerised tomography (CT) scans, electroencephalograms (EEG), psychometry, and ophthalmological methods.

\section{Patients and methods}

Our study comprised 25 patients with CMD and 30 with Duchenne dystrophy. Each was seen in our clinic between 1972 and 1977 (Table 1). Two girls were in the group of patients with Duchenne dystrophy; their ages at onset were 6 and 12. They are still walking at ages 16 and 17 years, but pseudohypertrophy of the calves was prominent in each. One had had a brother with typical Duchenne dystrophy who had died at age 12 with respiratory distress, with confirmation of the diagnosis at necropsy. IQs of these girls were 45 and 80 . They may have the autosomal recessive limb girdle dystrophy, but clinical resemblance to Duchenne dystrophy is strong.

CT scans were carried out with the EMI 1000 or 1010 equipment. Brain atrophy was diagnosed by an enlargement of internal and external cerebrospinal fluid spaces. ${ }^{7}$ Cortical signs refer to qualitative evaluation of basal, insular, and interhemispheric cisterns and cortical sulci. Cisterns and sulci which showed enlargements of 3-5 mm were classified as slight, more than $5 \mathrm{~mm}$ as considerable. Internal signs refer also to qualitative evaluation.

IQ (or DQ) was measured using a modified

Table 1 Patients with progressive muscular dystrophy

\begin{tabular}{lll}
\hline & $C M D(n=25)$ & Duchenne $(n=30)$ \\
\hline Male : female & $11: 14$ & $28: 2$ \\
Average age (years) & $7 \cdot 9$ & $13 \cdot 2$ \\
Range & $16 \mathrm{~m}-17 \mathrm{y} 7 \mathrm{~m}$ & $4 \mathrm{y} 11 \mathrm{~m}-20 \mathrm{y} 8 \mathrm{~m}$ \\
\hline
\end{tabular}


Binet-Simon developmental test. Routine neuroophthalmological examinations were attempted but very often a complete examination was not possible because of extensive physical and mental disturbances.

\section{Results}

CT scans were done on 25 patients with CMD and 30 with Duchenne dystrophy. The most characteristic finding in CMD was a low density area in the white matter, and this was present in $14(56 \%)$ patients (Table 2). Ventricular dilatation also was noted in 20 $(80 \%)$ out of 25 , and cortical atrophy in $16(64 \%)$. In one case of CMD, asymmetry of the lateral ventricle was observed. In Duchenne dystrophy, slight ventricular dilatation and cortical atrophy were observed in $18(60 \%)$ and $9(30 \%)$ respectively, but in no case was there a low density area in the white matter.

In CMD, half the patients had a low density area in the white matter in addition to cerebral atrophy, and only $3(12 \%)$ showed normal CT scans (Table 3). In Duchenne dystrophy, slight cerebral atrophy was observed in $20(67 \%)$ patients, and in $10(33 \%)$ there were no abnormal CT findings. Typical CT findings are shown in Figs 1 and 2.

The relation between CT findings and IQ is shown in Fig. 3. In CMD, those with a low density area in addition to cerebral atrophy and those with cerebral

Table 2 CT findings

\begin{tabular}{lll}
\hline$C T$ findings & $C M D(n=25)$ & Duchenne $(n=30)$ \\
\hline $\begin{array}{l}\text { Low density area in white } \\
\text { matter }\end{array}$ & $14(56 \%)$ & 0 \\
$\begin{array}{l}\text { Slight } \\
\text { Moderate }\end{array}$ & 6 & \\
$\begin{array}{l}\text { Cerebral atrophy } \\
\text { Ventricular dilatation }\end{array}$ & $20(80 \%)$ & $18(60 \%)$ \\
$\quad \begin{array}{l}\text { Slight } \\
\text { Moderate }\end{array}$ & 12 & 18 \\
$\begin{array}{l}\text { Cortical atrophy } \\
\quad \text { Slight }\end{array}$ & $16(64 \%)$ & $9(30 \%)$ \\
$\quad$ Moderate & 9 & 9 \\
Asymmetry of lateral & 7 & \\
$\quad$ ventricle & $1(4 \%)$ & 0 \\
Normal findings & $3(12 \%)$ & $10(33 \%)$ \\
\hline
\end{tabular}

Table 3 CT findings

\begin{tabular}{lcc}
\hline$C T$ findings & $\begin{array}{l}C M D \\
(n=25)\end{array}$ & $\begin{array}{l}\text { Duchenne } \\
(n=30)\end{array}$ \\
\hline Low density area + cerebral atrophy & $12(48 \%)$ & 0 \\
Low density area & $2(8 \%)$ & 0 \\
Cerebral atrophy & $8(32 \%)$ & $20(67 \%)$ \\
Normal findings & $3(12 \%)$ & $10(33 \%)$ \\
\hline
\end{tabular}

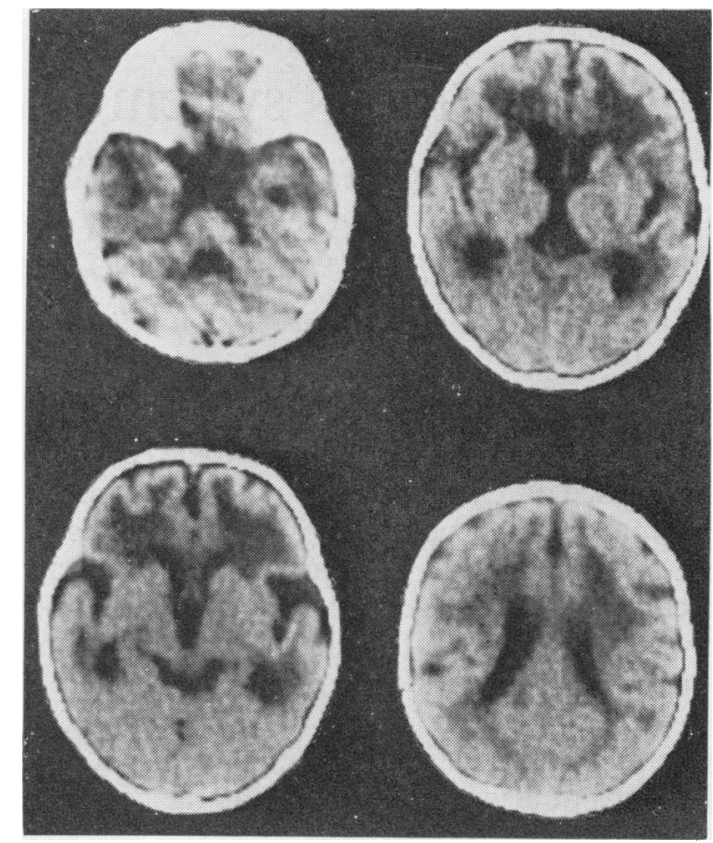

Fig. $1 C T$ scan of a 16-month-old girl with CMD. $A$ diffuse, low density area was observed in the white matter in bilateral frontal lobes which extended to the bilateral frontoparietal region symmetrically. Cortical atrophy was noted in bilateral frontal lobes, but ventricular dilatation was slight.

atrophy alone had an extremely low IQ compared with those with only a low density area or a normal CT scan. Among the patients with Duchenne dystrophy, there were many with a low IQ in those with cerebral atrophy, but in those with normal CT findings only 3 had a low IQ.

The relation between CT findings and EEG in patients is shown in Table 4. Seizure discharges such

Table 4 Relationship between CT findings and EEG in 25 patients with CMD and in 30 patients with Duchenne dystrophy

\begin{tabular}{lllll}
\hline \multicolumn{4}{c}{ EEG findings } & \\
\cline { 2 - 5 } CT findings & $\begin{array}{l}\text { Spike or } \\
\text { sharp wave } \\
\text { complex }\end{array}$ & Spike & $\begin{array}{l}\text { Slow } \\
\text { wave }\end{array}$ & Normal \\
\hline CMD $(n=25)$ & & & & \\
Low density area + & 3 & 2 & 0 & 7 \\
$\quad$ cerebral atrophy & 3 & 1 & 0 & 1 \\
$\begin{array}{l}\text { Low density area } \\
\text { Cerebral atrophy }\end{array}$ & 0 & 1 & 3 & 3 \\
Normal findings & 0 & 1 & 1 & 1 \\
$\begin{array}{l}\text { Duchenne }(n=30) \\
\text { Cerebral atrophy }\end{array}$ & 0 & 1 & 7 & 12 \\
Normal findings & 0 & 0 & 5 & 5 \\
\hline
\end{tabular}




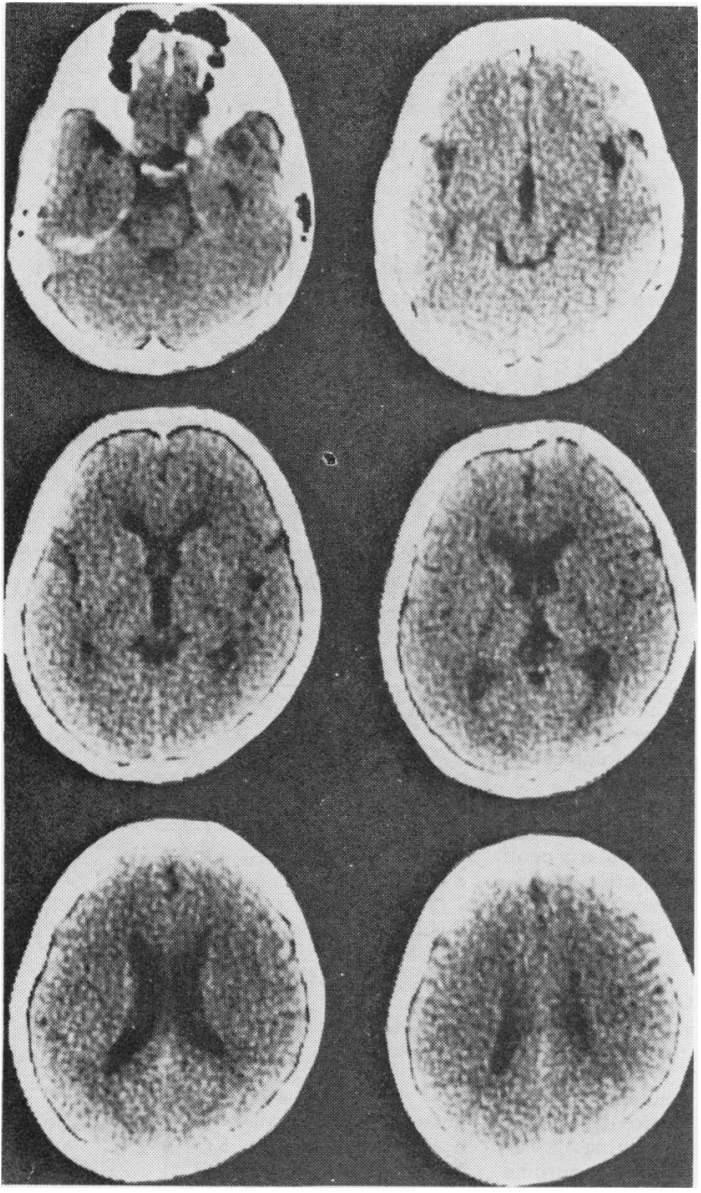

Fig. 2 CT scan of a 20-year-old youth with Duchenne dystrophy. There was slight enlargement of the interhemispheric fissure and both Sylvian fissures; the cerebral convexity sulci were also apparent.

as spike or sharp wave complex and spike, were most often seen in those with a low density area in addition to cerebral atrophy in CMD, and among these patients epileptic seizures occurred in 3 . Half of the patients with CMD had EEG abnormalities, but in those with Duchenne dystrophy, spike was observed in only one case and in no patient did epileptic seizure occur.

Fig. 4 shows the relation between CT findings and the stage of disability. In CMD, those with a low density area in addition to cerebral atrophy showed severe motor disability and none could walk. Among 25 with CMD, only one could walk and again there was a low density area seen on CT scan. In Duchenne

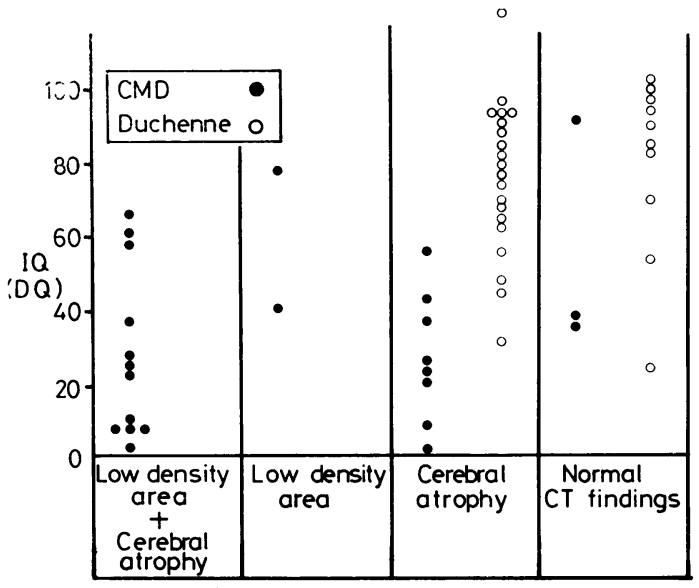

Fig. 3 Relationship between CT findings and IQ.

dystrophy, those with cerebral atrophy showed severe motor disability compared with those with normal CT findings.

The relationship between CT findings and age is shown in Fig. 5. In CMD, severe CT findings were seen in the younger age group, but in Duchenne dystrophy, cerebral atrophy was observed in the older patients.

Fig. 6 shows the relation between CT findings, IQ, and age in patients with Duchenne dystrophy. It was interesting that in these cases the older the patient, the more severe were the CT findings.

On ophthalmological examination (Table 5), a high incidence of myopia, weakness of the orbicularis oculi, lack of Bell's reflex, and blinking at rare intervals were seen in those with CMD. No pigmentary retinal degeneration was found and cataracts were rare. One important finding in this study was bilateral optic atrophy noted in several cases. Three out of 21 patients with CMD were diagnosed as having optic nerve atrophy and 6 more cases were suspect. Among those with Duchenne dystrophy, one was suspected to have optic atrophy. In 3 diagnosed as having optic atrophy in CMD, all had a low density area in the white matter in addition to cerebral atrophy on CT examination. In 5 suspected cases, a low density area was found in 2 $(40 \%)$ and cerebral atrophy in $3(60 \%)$. One case of Duchenne dystrophy was clearly diagnosed as type I Duane's syndrome, and one case of CMD was suspected to be type II Duane's syndrome. In a case of Duchenne dystrophy, lattice degeneration of the equatorial retina was found. Macular degeneration of unknown aetiology was observed in one eye of a patient with Duchenne dystrophy. 


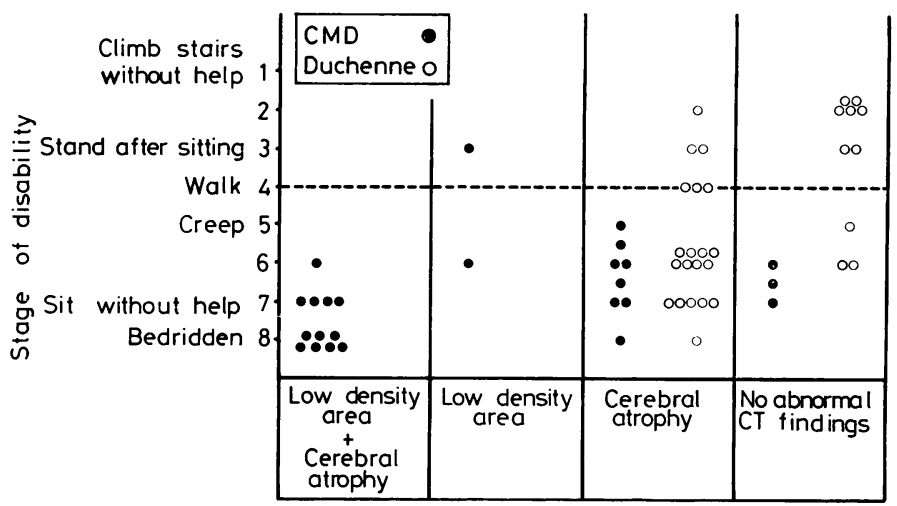

Fig. 4 Relationship between CT findings and stage of disability.

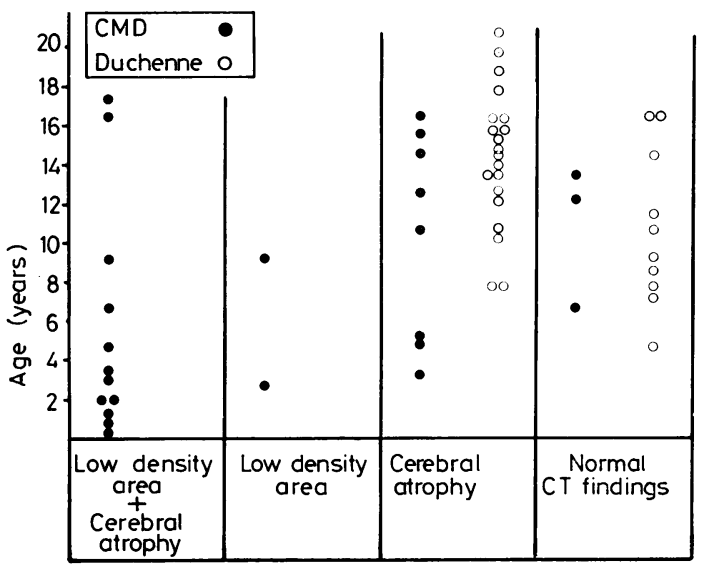

Fig. 5 Relationship between CT findings and age.

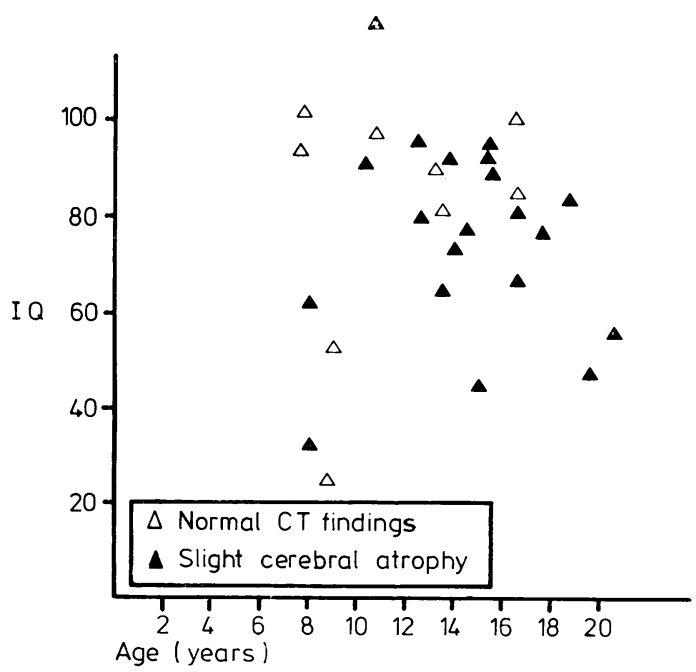

Fig. 6 Correlation between $C T$ findings, IQ, and age in patients with Duchenne dystrophy.
Table 5 Ophthalmological findings in 25 patients with $C M D$ and in 32 patients with Duchenne muscular dystrophy

\begin{tabular}{|c|c|c|c|c|}
\hline Findings & $\begin{array}{l}C M D \\
(n=25)\end{array}$ & & $\begin{array}{l}\text { Duchenne } \\
(n=32)\end{array}$ & \\
\hline $\begin{array}{l}\text { Male : female } \\
\text { Average age (years) }\end{array}$ & $\begin{array}{c}11: 14 \\
7.9\end{array}$ & & $\begin{array}{l}29: 3 \\
13.6\end{array}$ & \\
\hline Ophthalmological & & & & \\
\hline Myopia & $9(36 \%)$ & & $5(16 \%)$ & \\
\hline $\begin{array}{l}\text { Hypermetropia } \\
\text { Weakness of }\end{array}$ & & & $1(3 \%)$ & \\
\hline orbicularis oculi & $14(56 \%)$ & & $3(9 \%)$ & \\
\hline Epicanthus & $3(12 \%)$ & & $1(3 \%)$ & \\
\hline Cataracts & $2(8 \%)$ & & $1(3 \%)$ & \\
\hline $\begin{array}{l}\text { Optic nerve atrophy, } \\
\text { diagnosis } \\
\text { established }\end{array}$ & $3(12 \%)$ & $9(36 \%)$ & 0 & $1(3 \%)$ \\
\hline $\begin{array}{l}\text { Optic nerve atrophy, } \\
\text { suspected }\end{array}$ & $6(24 \%)$ & & $1(3 \%)$ & \\
\hline $\begin{array}{l}\text { Macular degeneration } \\
\text { of unknown }\end{array}$ & & & & \\
\hline aetiology & $\mathbf{0}$ & & $1(3 \%)$ & \\
\hline $\begin{array}{l}\text { Lattice degeneration } \\
\text { of retina }\end{array}$ & 0 & & $1(3 \%)$ & \\
\hline Duane's syndrome & $\begin{array}{c}1(4 \%) \\
\text { suspected }\end{array}$ & & $1(3 \%)$ & \\
\hline $\begin{array}{l}\text { Microphthalmos } \\
\text { Hypoplasia iridis }\end{array}$ & 0 & & $1(3 \%)$ & \\
\hline
\end{tabular}

\section{Discussion}

The association of intellectual impairment with Duchenne dystrophy has long been recognised. ${ }^{8-9}$ Several studies have shown that there is no correlation between IQ, age, and the duration or severity of the disease. ${ }^{9-11}$ The IQ range in patients with Duchenne dystrophy showed a normal distribution curve with a shift to the left, and about one-third of those with Duchenne dystrophy had an IQ below $75 .{ }^{12}$ In the present study, 10 out of 30 patients with Duchenne dystrophy had an IQ below 75 and there was no correlation between IQ, age, and severity of the disease.

In a neuropathological study, Rosman and Kakulas $^{1}$ reported abnormalities in the brain of patients with muscular dystrophy. Dubowitz and 
Crome ${ }^{13}$ reported a necropsy study of 21 cases of Duchenne dystrophy and concluded that, with one exception, all the brains were normal in weight and most of them showed no histological abnormality. Refsum et al ${ }^{14}$ demonstrated that 5 out of 10 patients with dystrophia myotonica showed a progressive ventricular enlargement on repeated pneumoencephalography.

CT study of our patients with Duchenne dystrophy showed slight cerebral atrophy in $20(67 \%)$ out of 30 cases. These patients had severe motor disabilities compared with those with normal CT findings. Repeated CT examinations were not done, but the fact that the older the patient, the more severe were the CT findings suggests a slowly progressive cerebral degeneration in Duchenne dystrophy as is the case in dystrophia myotonica. The disorder manifests itself insidiously with regard both to muscular phenomena and cerebral degenerative changes, and one may assume that these changes are manifestations of a basic metabolic disorder.

In CMD, the most characteristic CT finding was the low density area in the white matter found in 14 $(56 \%)$ out of 25 patients. Cerebral atrophy was also seen in $20(80 \%)$ of them. There was no correlation between age, CT findings, and motor disability in those with CMD. Moreover, the younger age group showed rather severe CT findings and a more extensive motor disability than was seen in the older patients. These findings suggest that damage to the nervous system may occur at an early vulnerable stage of development in patients with CMD, and that the pathogenesis of CMD may differ from that of Duchenne dystrophy. It is interesting that in all 8 necropsy cases quoted in Japanese reports the muscle lesion was dystrophic, while abnormalities in the central nervous system were not dystrophic or degenerative, but rather dysplastic or dysgenetic. In this paper, we observed CT findings of only one variant of CMD, that is, the Fukuyama type. Studies are now in progress to compare the CT findings of the other variants of CMD which are not associated with intellectual impairment.

A low density area in the white matter in CT scans is seen in various diseases; those diseases with degeneration affecting primarily cerebral white matter and multiple sclerosis ${ }^{15}$ are important in differential diagnosis. Eiben and DiChiro ${ }^{16}$ suggested that early frontal lobe localisation and relative sparing of occipital lobes were inconsistent with a diagnosis of adrenoleucodystrophy. In our patients with CMD, the low density area was particularly prominent in the white matter of the frontal lobes. This CT finding helps to differentiate CMD from adrenoleucodystrophy.
On ophthalmological examination ${ }^{17}$ weakness of the orbicularis oculi associated with the lack of Bell's reflex is often observed in CMD; blinking is rare in these patients. Both can be explained by the atrophy of the facial muscles. Subcortical cataracts and pigmentary retinal degeneration which have been observed in myotonic dystrophy were not seen in any of our patients. The eye symptoms in cases of progressive muscular dystrophy are quite different from those of myotonic dystrophy. Atrophy of the optic nerve is sometimes associated with CMD. These patients have a low density area in the white matter, in addition to cerebral atrophy on CT scan, and also a severe motor delay. We consider optic nerve atrophy to be one of the most important findings in CMD patients. Duane's syndrome is usually an expression of an autosomal dominant unit, while Duchenne dystrophy is sex linked. A combination of these two anomalies would point to a combination of two different genetic defects and would be rare.

Our findings suggest that progressive muscular dystrophy is not only a muscular disorder but also one which affects the central nervous system.

This paper was presented in the IVth International Congress on Neuromuscular Disorders, Montreal, Canada, September 1978.

We thank Dr M Ohara for assistance with the manuscript.

\section{References}

1 Rosman N P, Kakulas B A. Mental deficiency associated with muscular dystrophy. Brain 1966; 89: 769-87.

2 Kamoshita S, Konishi Y, Segawa M, Fukuyama Y. Congenital muscular dystrophy as a disease of the central nervous system. Arch Neurol 1976; 33: 513-6.

3 Iwase K, Watanabe K, Sato I. A case of congenital muscular dystrophy. Pediatrics (Tokyo) 1971; 12: 363-7.

4 Kasubuchi Y, Haba S, Wakaizumi S, Shimada M. An autopsy case of congenital muscular dystrophy accompanying hydrocephalus. Brain and Dev 1974; 6: 36-41.

5 Murakami S, Konishi Y, Takamiya M, Tsukagoshi $\mathbf{H}$. Congenital muscular dystrophy associated with micropolygyria. Acta Pathol Jpn 1975; 25 : 599-612.

6 Fukuyama Y, Haruna H, Kawazura M. A peculiar form of congenital progressive muscular dystrophy. Paediatr Univ Tokyo 1960; 4: 5-8.

7 Meese W, Lanksch W, Wende S. Cerebral atrophy and computerized tomography. Aspects of a qualitative and quantitative analysis. In: Lanksch W, Kazner E, eds. Cranial computerized tomography. Berlin: SpringerVerlag, 1976: 222-32.

8 Allen J E, Rodgin D W. Mental retardation in association with progressive muscular dystrophy. Am J Dis Child 1960; 100: 208-11. 
9 Worden D K, Vignos P J, Jr. Intellectual function in childhood progressive muscular dystrophy. Pediatrics 1962; 29: 968-77.

10 Zellweger H, Hanson J W. Psychometric studies in muscular dystrophy type IIIa (Duchenne). Dev Med Child Neurol 1968; 9: 576-81.

11 Prosser E J, Murphy E G, Thompson M W. Intelligence and the gene for Duchenne muscular dystrophy. Arch Dis Child 1969; 44: 221-30.

12 Dubowitz V. Mental retardation in Duchenne muscular dystrophy. In: Rowland L P, ed. Pathogenesis of human muscular dystrophies. Excerpta Medica ICS 404. Amsterdam: Excerpta Medica, 1977: 688.

13 Dubowitz V, Crome L. The central nervous system in Duchenne muscular dystrophy. Brain 1969; 92: 805-8.

14 Refsum S, Lønnum A, Sjaastad O, Engeset A. Dystrophia myotonica. Repeated pneumoencephalographic studies in ten patients. Neurology 1967; 77: 345-8.
15 Gyldensted C. Computer tomography of the brain in multiple sclerosis. Acta Neurol Scand 1976; 53: 386-9.

16 Eiben R M, DiChiro G. Computer assisted tomography in adrenoleukodystrophy. J Comp Ass Tomogr 1977; 1: 308-14.

17 Honda Y, Yoshioka M. Ophthalmological findings of muscular dystrophies: a survey of 53 cases. $J$ Pediatr Ophthalmol Strabis 1978; 15: 236-8.

Correspondence to Dr Mieko Yoshioka, Department of Molecular, Cellular, and Developmental Biology, University of Colorado, Boulder, Colorado 80309, USA.

Received 31 July 1979 